\title{
Stanislavski's System in Musical Theatre Actor Training: anomalies of acting song
}

The principles underpinning current acting approaches in musical theatre are primarily based on, and indebted to, Stanislavski's acting 'System'. Though the musical theatre acting literature fails to formally explain the modes of appropriation or varying legacies of Stanislavski's tenets (a task I will briefly cover), the pervasive reception given aspects of his systematic preparations may rest, in part, on the apparent logic of a methodology that enables actors, during the process of preparing for a role, to approach a song and its lyrics as though they would a play and its spoken text. Moreover the holistic way Stanislavski perceived the actor's process (particularly in the latter part his career), reinforced the intrinsic coalescence of psychophysical work and active engagement with emotions (or broadly, components of affective and sense memory), and this approach resonates with the integrationist ideals in modern musical theatre actor training which seek to combine, in an emotionally invested way, the essential elements of acting, singing and movement. However, when preparing to act through song, the integrationist stance of psychophysical characterisation may be challenged by the vocal technical requirements of learning the music, which alongside musically affective experiences, may not necessarily cohere with a monological acting exercise of, say, speaking the lyric-text. I will stage a critical discussion around such song acting anomalies and develop my reflections as I consider the function of breath as a lynchpin in song acting. If arousal of, or engagement with, emotion, through a combinatory sequence of analytical and physical action, is fundamental to psychophysical work, in song acting that process is exponentially problematized, generating a complex relationship between technical mastery and emotional availability.

Keywords: Musical theatre, actor training, Konstantin Stanislavski, song acting, breath, psychophysical, organic, integration, emotion, action score.

Zachary Dunbar is Research Coordinator in Theatre, and also Senior Lecturer in Music Theatre at the Victorian College of the Arts and Melbourne Conservatorium of Music, The University of Melbourne. Zachary initially pursued a career as an international concert pianist before his interest in theatre converged with music. He works professionally as a theatre director, composer and writer, with original works staged in the UK, and has scholarly publications in the field of Music theatre, postdramatic theatre, and in Greek tragedy. 


\section{Stanislavski's System in Musical Theatre Actor Training: anomalies of acting song}

Zachary Dunbar

Acting through song is an enormous challenge for an actor; it requires as much attention to rhythm and intention as a Shakespeare monologue, with the additional demand of making music. [...] [M] usic must be made, and theatrical music can only be made with a true understanding of the way the text and the music combine (and sometimes work against each other) to tell a story'. (Jason Robert Brown, in Streeton and Raymond 2014: 78)

Stanislavski worked imaginatively and pragmatically when he trained singers to act, perceiving no difference, at least from a fundamental basis of theatre performance, between the actor and the singer, and submitting the latter, as part of the work he conducted in the Bolshoi Opera Studio training, to systematic classes in voice, diction, movement and acting (Carnicke and Rosen 2014: 126). This undifferentiated approach toward the two disciplines, originating as it did out of the post-Wagnerian zeitgeist for holism in the arts, also reflected his disposition about music and drama, whose laws he believed overlapped, and whose expressive elements, particularly the nature and function of tempos and rhythms, gave actors and singers the wherewithal to perform in a dramatically vital and credible way. ${ }^{1}$

A survey of current training manuals for actors in musical theatre suggests that Stanislavski's ideals and principles are alive and well, even though the literature fails to formally explain their means of appropriation or historical legacy. While this unresolved task demands a lengthier critical survey than the one offered here, my central discussion will initially cover the pervasive reception given to aspects of his systematic preparatory work. The reception rests, in part, on an apparent logic of a methodology that enables actors, during the process of preparing for a role, to approach a song and its lyrics as they would a play and its spoken text. Moreover the holistic way in which Stanislavski perceived the actor's process, which emphasised, particularly in the latter part his career, the intrinsic coalescence of psychophysical 
work and emotions (or broadly, affective and sense memory), resonates with the integrationist ideals in modern musical theatre actor training: to combine the essential elements of acting, singing and movement in an emotionally invested way.

\section{Survey.}

H. Wesley Balk's book The Complete Singer-Actor $(1977)^{2}$ is seminal in the way in which it suggests a synthesis of opera and theatre training approaches, which in the tradition of Stanislavski-style training, provides a logical preparatory framework; Thomas Burgess and Nicholas Skilbeck (2000) stage games to bring drama and music into a 'creative interplay' (17), and these exercises represent a purposeful amalgamation of skills founded on Stanislavski's integrationist principles; David Ostwald's (2005) key premise for 'believable' actor-singing is supported by character-building techniques that are mainly Stanislavski-based.

Recent manuals increasingly respond to the specific multidisciplinary and stylistic challenges posed by the musical theatre genre, and these books complement the Stanislavski legacy with voice- and movement-based actor training approaches. Allison Bergman and Tracey Moore (2008) offer workshop-style exercises on the structure and performance of song and propose foundational knowledge in, and practice of, the voice as a prologue to acting; Joe Deer and Rocco Dal Vera (2008), a director and a voice specialist respectively, offer a course-work style pedagogy and draw on their wide-ranging experience; their approach to the various styles of musical theatre repertoire are underpinned by Stanislavski-style text-analysis; Paul Harvard (2013), as a trained actor-musician in the European tradition, threads common sense anecdotes through eclectic acting approaches drawn from Stanislavski, Meisner and Laban techniques.

In musical theatre training, song acting demands a complex set of analytical and physical preparations, given that actors need to understand what the song is saying through the lyrics, and to sing the music in a safe and compelling way. It is not surprising therefore to find aspects of the psychophysical system pioneered by Stanislavski underpinning current actor training in this field. An actor, by coordinating in-tandem work between analytical and physical exercises, and resourcing personal emotion, observation and imagination, ought to fully (or 
'truthfully' $)^{3}$ live the role in a Rodgers and Hammerstein or Sondheim musical as they would a character in a Shakespeare or Chekhov play. The full range of processes underpinning such psychophysical work in the context of musical theatre, and the inextricable role that emotion, imagination and observation play cannot be fully discussed in this essay. But in order to distinguish aspects that arise regularly and centrally in song acting - namely, the implications of organic-ness and the notion of analysing text in units of action - I offer this brief précis.

\section{Psychophysical aspects of the system: organic-ness of emotion and the notion of units of action.}

The unique integrative form of psychophysical training, which essentially aims to inculcate within actors an interdependent sense of their inner-personal psyche and outer-physical characterisation, operates on the principle that a physical action generates psychological reactions, and vice versa (Merlin 2007: 23-5). The primary blueprint for all psychological and physical work is the dramatic text - it is in the world and the words of the play that actors interpret the intentions of the author, and through which they find their way to (and through) the character and dramatic scenes. ${ }^{4}$ Arguably, the intervention of text during the preparatory work, whether in the form of analytical engagement, or commitment to memory, has differed throughout the development and subsequent application of the 'system'.

The systematic process, whereby an actor progressively inhabits the character's actions, requires (intrinsically) an interlayering of personal emotional and imaginary responses that are actualised through physically active exercises (Merlin, 154-61). Stanislavski continually worked out the relationship of the physical to the psychological with varying emphases: in the beginning stages, the analytical exercises were pre-eminent while the physical exercises served as a measure to anchor the emotional state of the actor during performance; later in his life, fearing that performances risked becoming mechanised and sterile iterations of his acting process, he stressed that there ought to be an "ongoing organic" relationship (perezhivanie, or “emotional experience”) (Krasner 2014: 197). While the metaphor of 'organic' has wide-ranging contexts and implications in theatre practice today, it is in the totalising, interdisciplinary schema of an actor's work - such as suggested by Gutekunst and 
Gillett (2014) 'who seek to 'integrate impulse, language, mind, body and voice' (3) that we may discern an updated appropriation of Stanislavski's notion of organicness, or the integrative actions of mind and body, and emotion memory and technique.

The permutations and revisions of the usages of Stanislavski's 'system' are many and extensive. Bella Merlin's 'toolkit' approach (Merlin 2007) offers a coherent overview of their principles and preparations which is widely used today. Broadly, the actor, when encountering text may, preliminarily, establish given circumstances, magic ifs, 'bits', objectives, subtexts, and this process if led by interrogations that are factual (who, when, where) and interpretive (why, how, and for what reason); intermediately, the actor works on the more intrinsically physiological aspects of the text (as score) by deciphering aspects of tempo-rhythm alongside emotion memory work (articulated as Method of Physical Actions); and latterly, the actor may engage in modes of improvisation and retrospective text analysis (conveyed as Active Analysis). The notion of generating a logical sequence, or chain of actions, is a key exercise (a device central to song acting, which I shall discuss next) that effectively anchors, or maps out, the psychophysical aspects of a character journey. The premise of such an exercise, according to Stanislavski, is that '[actors] perform actions in real life with extraordinary logic and sequence that have been built into our muscles by years of habit' (Benedetti, 507).

One of the elemental procedures, in the first instance, requires an actor to understand a character's objectives and counter-objectives (her 'wants' and reactions of others to her wants), which may be broken down, according to the dramatic scene, as 'bits', or units of action (Merlin, 70-90; Carnicke 2009: 214). While an actor works on this exercise, psychological and physical considerations come into play. As Merlin describes it, 'an appropriately chosen sequence of physical ACTIONS will provoke interesting psychological ACTIONS, and together can create the role that you're embodying (Merlin 138). Present-day actor trainers in the Stanislavski tradition, such as John Gillett, uphold a similar preparatory principle wherein an actor is advised to map out his or her psychophysically prepared actions to ensure that 'the inner life of the character is underway' (Gillett 2014: 184, 186, 200). The way this structured 
preparation operates in performance, according to Stanislavski, is likened to an unbroken line of events, which signifies

The endless number of ideas, objects of attention, communication, Tasks, wishes and actions, moments of truth and belief, emotion memories, Adaptations each form up in ranks. The inner drives pass through them, activate the Elements [...]'.6 (Benedetti 2008: 292)

\section{Some appropriations of psychophysical-type work in musical theatre acting.}

Almost without exception, the musical theatre song acting toolkit involves aspects of the psychophysical-type work I described. When Bergman and Moore (2008) discuss the acting element, they cover 'magic ifs', storytelling, and given circumstance (2930). Harvard (2013) explains the Stanislavski 'basics' of acting through song in his introductory chapters, while Deer and Dal Vera (2008) devote the entire first two chapters of acting fundamentals (15-43) to the analytical approach of song as dramatic text, with the proviso that emotion, observation and imagination are intertwined in the process: 'find[ing] the character through emotional and psychological means [...] eventually result[s] in physical and vocal choices that are stageworthy' (11). The appropriation of Stanislavski-based tenets, such as the integration of emotion and technical exercise, and the notion of scoring of actions in delineated units have, within musical theatre acting, common as well as slightly variable usages, especially in acting out the lyric-text.

\section{Acting the lyric-text.}

One of the primary ways in which psychophysical-type work combines with understanding a character's emotional journey in song is through 'actioning' the lyrictext, as though it represented a spoken monologue. Stanislavski, when working with opera singers, instructed them to treat the lyrics of songs by composers such as Rimsky-Korsakov and Tchaikovsky as monologues (Carnicke and Rosen: 127). Similarly, the guidelines in musical theatre acting emphasise the important function of the lyric-text for invoking images, emotions, and physical gestures, alongside delineating the character's objectives and their related tactics (Harvard, 272; Deer and 
Dal Veera, 231). Stanislavski proposed that actors investigate a character's needs, and the ways that they may set out to achieve those needs, in 'bits' or units of scenic material, while the use of verbs, he suggested, vividly actualised these needs and their objectives: 'The hidden essence of a soliloquy in verse can only be made comprehensible through clear and precise shaping of the bits' (Stanislavski, cited in Benedetti 1999: 196).

The procedure in musical theatre acting, of breaking down a character's actions into units of tactical actions is designated, in the common jargon, as 'beat' changes. In this process, the use of transitive or 'doing' verbs (such as 'I arrest you', 'I pamper you', 'I debase you') is suggestive of Stanislavski's aforementioned notion of 'verbal action' and 'through-lines of actions' (Merlin 226-31). The current systematic practice of this process is rooted, in the American acting culture, through the legacy of Stella Adler's teaching (Adler 1988: 87-101), and in the UK, through the theatre work of Max Stafford-Clark (Caldarone and Lloyd-Williams, xvi-xx). Interpreting and actioning the text in such a manner is intended to hold in train a sequence of actions consisting of a detailed and co-ordinated narrative of images, actions, voice techniques, and movements, which are eventually internalised as a kind of action score.

In chapter five of Harvard's book, 'Creating a Performance Score', he suggests that actors use the 'lyrics of an individual song' to catalyse and guide creative explorations (Harvard, 72-90). Deer and Dal Veera offer templates which support the thinking processes of analysing song lyric-texts; the basis upon which actors may work out a character's actions in 'beat' changes are guided by categories such as given circumstances, objectives and dramatic outcomes (174-77, 181-6). Both authors reinforce the notion of interpreting lyric-text in 'beats' (i.e., a change in tactic to achieve a given objective): 'A song is more likely to have a beat shift clearly planted by the composer and lyricist' $(2008,170)$. Bergman and Moore similar teach how to develop 'behavioural specificity' in an 'action/tactic score', where 'for every beat or new thought, a new action is taken with the supposition that it will help the character achieve the want of the song' (107).

The conflict of learning music (tone) and drama (word) ${ }^{7}$. 
The words of a dramatic script and the notes of a music score are read and interpreted in a comparable manner because music, like words, can convey a dramatic narrative and give a sense of the outer and inner feelings of a character. Moreover, when we analyse music we easily slip into a shared language such as 'beats', 'intentions', 'tempo-rhythm', 'structure', 'phrases', and 'through-lines'. Yet, we are also aware that musical notation concretises sound in more or less exacting durations, rhythms and pitches, and such predetermined temporal-spatial frameworks demand from the actor a qualitatively different sense of spontaneity or performance experience from that accorded by text verse. Thus the musical (tone) and dramatic (lyric-text) elements that make up a song may engage the singing actor in mentally and physically different ways. And these polarising effects require, in the first instance, isolating or compartmentalising processes to allow mastery of the separate components, in the manner suggested by musical theatre practitioners.

Apart from the complex relationship of 'actions and words', within the musical parameters alone, Burgess and Skilbeck identify tensions created by combinations of musical 'rhythm, pitch, timbre (tone-colour) and volume, and their arrangement into a texture' (4). The meaning of words may not necessarily align to these different musical combinations, suggesting, as the composer Jason Robert Brown states (see introductory quote), that text and music may work against each other to tell a story. In for instance a lyric-text' such as 'Mary had a little lamb', we might understand, syntactically and semantically, the meaning straightaway, when the words are spoken to us. If however the lyric-text 'had' was sustained over several beats, the phonetic emphasis on the vowel 'ha' may evoke in the actor a different sensation for the phrase, and therefore convey a different meaning and sensation.

Burgess and Skilbeck, moreover, categorise two fundamental sets of training, which include physical elements ('relaxation', 'fitness, flexibility/control', 'concentration', 'awareness', 'imagination', and 'spontaneity) and also vocal elements ('voice production, rhythm and pulse, diction and appreciation of words', 'characterisation') (15-16). Adhering to the principle of psychophysical-type work, both pedagogues make the point that it is the actor's 'organisational task to combine these areas into a single co-ordinated act of sung theatre. [...] to transcend the separate performance 
disciplines involved in singing and acting at the same time to unite the many levels of meaning present in music and drama into a synthesis' (16). The complexity of training must eventually harness a 'kinesthetic awareness, emotional connection, action, and so on' (1). Towards this objective, Burgess and Skilbeck provide the actor, in the first instance, with set principles of voice practice (e.g., Patsy Rodenburg, Cecily Berry, Catherine Fitzmaurice, and Kristin Linklater) before launching into guidelines for acting. While Burgess and Skillbeck mix singing and acting specialties early in the actor's preparatory work. Deer and Dal Veera, on the other hand, reinforce the character-building and text-analysis work before elucidating on vocal considerations.

Overall, there is consensus among musical theatre pedagogues about the need to integrate learning, but technical security is required, first, before actors may engage fully with their emotional and imaginary faculties. Harvard suggests that, following technical mastery, the actor will be able to harness emotions so that, where 'emotions threaten to be too present in such a way that they interfere with expression, [...] [the actors] may distance [themselves] from the emotion without losing touch with it' (173). Such mastery may involve, for instance, muscular patterning, a physiological activity that entails learning the appropriate anatomical alignments to produce specific qualities that suit the style of a song. For instance, a 'twang' sound which boosts a quality of resonance and clarity; 'belt' which configures shouting and singing; or 'operatic/bel canto' which incorporates the more general open, pure lyrical tone. According to Harvard, 'muscular patterning' (and any accompanying conceptual imaging needed to sustain and repeat the patterning) precedes emotional spontaneity (Harvard, 183).

In summary, the coterminous construct implicit in Stanislavski's psychophysical work propounds a totalising process such that the dual-purposed activity of acting, through repetition and gradual refinement, eventually resolve anomalous effects generated through physical or mental work. According to Merlin, 'If you're working psychophysically, $[\ldots]$ : you can hop from one stimulus to another with equal affectivity' (2007: 148). In musical theatre pedagogy, the implicitness of toing and froing between singing and acting techniques, even if presented to the actor in particular orders of importance, mirrors the melding process of psychophysical work. Yet in 
learning song, physical technical mastery is required to allow an actor to control the emotional element. The idea of rising above and yet being a part of performance through technical mastery recalls Stanislavski's notion of Dual Conscious in which "self-control" is deemed to be a prerequisite for crafting a performance (Carnicke 2009: 2). This craft is also construed as the actor-singer's 'art' (Harvard 182).

Nonetheless it remains uncertain, or indeed speculative from the surveyed literature of musical theatre training, how transcendence of 'the separate performance disciplines involved in singing and acting' (Burgess and Skilbeck, see above) is achievable, or when, during initial key physical stages of muscular embedding, that emotional/imaginative responses are meant to intervene or interact with choices. How is the sensation of organic-ness (notionally, the state of being emotionally present or generative), meant to be constantly active and crucial in the micro-level of muscular alignments and anatomical awareness? When, or to what degree during rehearsal does sensing the tilt of the larynx, or the alignment of the neck muscles incorporate a character's impulses or objectives prompted by the lyrics? And how might we qualify a 'truthful' (i.e., spontaneous sounding) performance when to sing safely night after night, and therefore to trust in technique, overrides the spontaneous emotions that being in the moment may induce?

In the next section, I stage a discussion of this potentially conflicted state from the standpoint of the use of breath in acting song.

\section{Breath and the problem of integration when working on text and on music.}

The systematic study of the use of breath in actor training has undoubtedly helped dissolve the problematic in-your-head/intellectual versus in-your-body/physical work that actors experience during training. The use of breath also induces holistic experiences, arguably dissolving boundaries between visual, aural and physical senses $;^{8}$ the experiential implications of breath are well disseminated in Eastern practices such as yoga, and substantiated within Stanislavski-based training and research in the recent 'Cognitive' turn. ${ }^{9}$ It was Stanislavski's view that breath helped an actor to connect with emotions while melding inner and outer tempo-rhythms (Merlin, 34; Benedetti, 463-506). Breath is perceived as a lynchpin in mental and 
physical inter-activity, the 'psyche, [and] a key source of inspiration' (Gutekunst and Gillett, 107). The alignment of breath and text is also important for the inner-outer dynamic of psychophysical work because 'the breath carries the [inner] acting impulse on a wave through [outer] words and actions' (ibid.). Distilled formulaically: 'one thought, one sentence, one breath, one action' (Caldarone and Lloyd-Williams, $\mathrm{xx}$; Panet, 154).

In musical theatre, breath is absolutely essential for the singing actor's technique because it is required to sustain the music while conveying a character's objective through the thoughts conveyed in the lyric-text. As Harvard states, 'breathing as an actor is about marrying the amount of breath with the length of the thought', and when that thought is unnaturally stretched out over specific note durations, actors need to keep playing their actions (113). Deer and Dal Vera similarly acknowledge that 'all ideas initiate breath', and that the breath itself ought to be the 'same size as the idea they're about to express' (235-6). While in principle the alignment of breath to thought is conceivable and practicable, it assumes that the same quality or sensation ('size') of breath that plays or initiates an action is necessarily the same for that needed to sing a melody and convey the vocal qualities of that sound. Below, I describe a generic case that illustrates what I mean.

Scene: boy and girl are in love, but girl will not admit it. Cue: song. The boy's objective, as expressed in the lyric-text, is: 'I will get the girl to admit she loves me'. As he engagingly speaks the words, he gets a sense where each line of thought prompts different forms of strategies or tactics for 'getting the girl to admit love'. Actioning verbs (a process I described earlier which refines Stanislavski through Adler/Stafford-Clark) engages physical (i.e., gestural) and conceptual (i.e., imagemaking) actions; 'I lure you', 'I tempt you', 'I charm you', 'I lavish you' - each transitive verb activates actions that occur at the downbeat of each shift in tactic, delineating the moment in which the actor feels the character is closer to attaining, or losing ground in achieving the main objective. However, throughout this process, the actor speaking the lines is also cognisant of the quality of breath: it feels deep and full with the first unit of action, shallow and 'breathy' in the beat shift, agitated a few lines later, heavy and direct, and so forth. 
Subsequently (or preliminarily), an actor while learning the music also senses a dynamic and pace of breathing that is different than what speaking the lyrics as monologue prompted: perhaps the starting notes of the melody and its rhythmic configuration, on the action point, say, 'I lavish you', demands an energetic onset and an alignment of vocal physiology that contrasts with the psychological choice and complementary images evoked when speaking the lines; and throughout the song, where he has clearly delineated his 'units of action', he also senses quite different psychological images when embedding the melody to muscular memory through, for instance, sirening (singing the music in a relaxed 'ng' sound, with a soft palate). Given this scenario, the sensation of images, feeling and breath would appear to be substantially different when singing as opposed to speaking the text.

\section{The affective potency of the breath and sound.}

Leading voice specialists in actor training who promulgate the affective power of language and words on the body, and vice versa, note that: 'when language is explored through the body, it evokes [its own] specific physical properties', apart from the volition of the mind (Rodenburg 1993: 167). These varying 'physical properties' should make us realise the complex reactions we might have to the musical sound as well as to the musicality of words. Similarly, Kristin Linklater teaches actors that images have a tangible and primal connection to 'sound vibration and feeling', an experience which directly connects to the physiology of breathing (2006, 70). The interrelationship of image, voice, body and breath is in fact so contingently sensitised to soundings that an impulsive gesture, when accompanied with a phrase of text or music, may literally 'resound' with myriad images (Zinder 2013:157). Moni Yakim, in Creating a Character, demonstrates how acting choices are endlessly generative when breath 'ignites' the imagination simply through the incorporation of units of vowels and consonants (Yakim 1993; and appendices 21217). And according to Gutekunst and Gillett, 'vibrating sound through our whole body resonance connects us with our creative mind and communicates a subtlety in text and experience that goes beyond words and their literal meanings' (151).

Likewise, singing specialists concur that the interplay of physiological and affective sensations (during changes, adjustments, and realignments in the singing apparatus) 
involves vibratory mechanisms. Meribeth Bunch, in Dynamics of The Singing Voice (1994), provides early groundwork for the holistic shift in current singing pedagogy. Psychological and physiological aspects of singing (7-15) directly relate to the use of vocal, laryngeal, and nasal-oral sections, and these in turn correlate with the breathing apparatus such as the diaphragm, lungs, intercostal muscles and ribcage. In singing, the idealised well-balanced sound is a function of the way the exact amount of air pressure is processed in a tension-free and sustained way through the physical system. Thus, qualities of sound production correspond to the degree of correctness or appropriateness in the technical approach, especially when performing the singing requirements (such as style, tempo, dynamics, etc.) of a song. Yet, at the same time, the singer might feel herself happy, angry or saddened by the song as a whole, and this may affect the breathing patterns. For example in an angry state, human breathing tends to become shorter and shallower, which in turn may affect laryngeal muscles, constricting the air flow in the breathing passages. The diaphragm, lungs, intercostal muscles and ribcage in turn may be affected and, consequently, the singing process (105).

To summarise, the semantic and phonetic properties of lyric-text alone may affect the actors' senses and physiology (or breathing patterns), while the tonal and rhythmic properties of music may generate different ranges of physical and mental responses. Through breath alone, exponential sets of images, emotional registers, characterful gestures, sensory-motor sensations and vocal-physical alignments create complex experiences. Arguably, in some song repertoire, lyric-text writing and composition may converge in such a manner that an actor, without much effort, 'feels' connected viscerally and conceptually throughout the song. On the other hand, there are songs, particularly those that require a 'legit' or 'bel canto' style of singing ${ }^{10}$, where the concern for the quality of sound is foremost in the musical theatre actor's work. Recent research into the cognitive domains of acting remind us that the mind-body nexus continually operates on holistic levels of which an actor may not be fully conscious (Blair 2008). At the same time, preparation is a conscientious act; the actor is cognisant of anomalies even while attempting to maintain a holistic or fully integrated approach.

\section{Conclusion.}


Among the acting exercises handed down in theatre through Stanislavski's system, the connectivity of emotions and imagination with psychophysical work is perceived to be a significant precept. In musical theatre, the reception and applications of the system is problematized by the vocal-singing demands of song; for instance, it is argued, in musical theatre's acting guidelines, that technical security, during preparatory work, must necessarily come before emotional engagement. Moreover, the sought-after convergence between psychological and physical work, which may come about via the notion of scoring actions, must contend with multi-levelled sensorial and conceptual responses generated when an actor separately learns to sing the notes of the music and to speak the lyric-text. Such contention, especially evidenced in the role and function of breath, challenges the overarching ethos of organic-ness.

For the actor training in musical theatre, what is ultimately at stake in any acting process is how to negotiate or acknowledge emotional engagement throughout the preparatory process, rehearsal and performance, whether the activities are primarily physiological or conceptual. To be overcome with emotion, while singing, would ruin a performance because of the physiological effect on the vocal technique. At the same time, the oft-mentioned preference, in both industry and training institute, for 'actors who can't sing' over 'singers who can't act' implicates how the concept of emotional 'availability' or 'truth' remains an important issue. A UK-based colleague currently researching acting approaches in music theatre training programmes, notes a pervasive bias in training institutes which is reminiscent of old debates about opera singers who seek a balance between dramatic believability and (vocal) integrity of the music: 'it is much more veritable to watch an actor who is genuinely present and connected to the text at the expense of some vocal quality than an actor who is too conscious of making the performance note and tone perfect to fully invest in the specifics, a perfect example being Judi Dench's iconic performance of 'Send In The Clowns', from A Little Night Music, or more recently, Jane Horrocks' performance of 'Life is a Cabaret', as Sally Bowles in Cabaret'. ${ }^{11}$ Alternatively, an actor playing the character of Effie, in Dream Girls, or Elphaba, in Wicked, must present audiences, night after night, with a flawless belt sound. If in these circumstances, the stakes are high for the quality of vocal sound, how emotionally immanent must these 
performances be, and how relevant is Stanislavski-based training when the problematic of song acting is presented in this way?

I began this discussion with a comment about how Stanislavski had little cause to differentiate between the singer and the actor, believing as he did in the possibility of an acting craft that could supersede the conventional boundaries posed between these two performing arts, and respond to the specific performance demands upon the actor, whether vocal, physical or analytical. Wary of the embarrassing excesses of selfadulatory acting (Hodge 2000: 13; Merlin 2007: 37), and the habit of adopting a technique-for-technique's sake attitude, Stanislavski argued for an 'organic' connection between the technical means and their emotionally-connected ends, and developed his method in such a manner that it could 'speak to actors of different temperaments who wished to speak through different aesthetic styles' (Stanislavski, cited by Carnicke 2009: 3). The overtly pragmatic nature of the 'System' accommodates, to some extent, the wide variety of dramatic and musical styles in musical theatre. Nevertheless, the actor-in-training, when acting through song, must grapple with the relationship of the lyric-text and the musical elements, at times, learning processes that may require a separation of the emotional and physiological aspects, and coping with situations in which the music may evoke one thing and the lyric-text another. In truth, it reveals its inherent effectiveness when, as a system, it bends to such complex realities. 


\section{Notes}

${ }^{1}$ See Benedetti, 'Opera', in Stanislavski: his life and art, 255-70; also, Carnicke, and Rosen, 'A Singer Prepares: Stanislavsky and Opera', 120-138, and Renard, 'Stanislavsky on Voice and Movement: contexts, concepts and content', 103-19, both in R. Andrew White (ed.), The Routledge Companion to Stanislavsky, London: Routledge, 2014. The term 'totalising' has different usages and connotations. Apart from concepts gleaned from art and culture, Stanislavski was influenced by a number of emerging ideas in science-based thinking, notably in psychology, the ontology of nature, how machines operate, etc. (see Rose Whyman, The Stanislavsky System of Acting: Legacy and Influence in Modern Performance, Cambridge University Press, 2011). By calling Stanislavski's system a form of totalised training, I imply that it operates as 'more-than-the-sum-of-parts', whereby the 'parts' are derived as much from an actor's personal experience as environmental and ideological influences.

${ }^{2}$ Balk's updated work, Performing Power: A New Approach for the Singer-Actor. Minneapolis: University of Minnesota Press, 1985.

${ }^{3}$ Truth, insofar as the actor, when embodying a character, projects the illusion of spontaneity, as though the words were being made up in the moment - the 'creation of the living word' (Merlin 2007: 17) as Stanislavski put it - and not a static display or representation of an emotion or attitude. In musical theatre performance, the notion of 'truth' in performance is greatly complicated by the wide range of representative genres, from pantomime and Brechtian forms to conventional naturalism and commercial pop-rock styles. Songs too may function in a diegetic or non-diegetic way and therefore challenge how an audience and/or performer experiences or perceives 'truthfulness'.

${ }^{4}$ Arguably other factors are involved in the creation of character (not just the text), and these incorporate the actor's personal experience, the 'communion' with other actors, and ongoing observations of life which feed the life of the character role in rehearsal and performance (see endnote 1).

${ }^{5}$ Stanislavski developed his 'system' broadly in three phases: beginning initially with the emphasis on sense-emotion memory, in his First Studio work (1911/12), which eventually influenced the American 'studio method' work; a middle period, during the interwar years as the Soviet worldview of assembly-line societies took hold, and where a teleological and physio-mechanical development of the work led to notions of 'through-lines' of action, otherwise known as the 'Method of Physical Actions'; and a final phase that represented a 
kind of synthesis or 'organic' perception of emotions, improvisation and text analysis (Krasner 2014: 196-7).

${ }^{6}$ The linear sequence of actions correlated with the metaphor of a "filmstrip" (kinolenta). Stanislavski wanted actors to maintain a stream of mental visualisations as they performed (Krasner 2014: 227).

${ }^{7}$ For a historical overview of the word-tone relationship, see Don Harrán, Word-Tone Relations in Musical Thought: from antiquity to the seventeenth century. NeuhausenStuttgart: American Institute of Musicology: Hänssler Verlag, 1986. Though I focus the discussion on the lyric-text, it is by no means the only aspect of song where changes in a character's actions occur. Such changes might be signalled in shifts within musical accompaniment, harmony, tempo, or indeed directions in the libretto.

${ }^{8}$ Jane Boston and Rena Cook (eds.), Breath in Action: the art of breath in vocal and holistic practice, London; Philadelphia: Jessica Kingsley, 2008.

${ }^{9}$ Rhonda Blair, The Actor, Image and Action: acting and cognitive neuroscience, Abingdon: Routledge, 2008; John H. Lutterbie, Toward a General Theory of Acting: cognitive science and performance, London: Palgrave Macmillan, 2011; Rick Kemp, Embodied Acting: what neuroscience tells us about performance, Abingdon: Routledge, 2012.

${ }^{10}$ Songs in musicals by Rodgers and Hart, Rodgers and Hammerstein, or Andrew Lloyd Webber may fall into this category.

${ }^{11}$ As mentioned in an email attachment to me from Sherrill Gow, August 21, 2015). Gow's current exploration of actor training approaches in musical theatre is part of a practice-led PhD research entitled, '(Re)Examining Actor Training in Musical Theatre Contexts', Royal Central School of Speech and Drama, University of London, forthcoming 2019. 


\section{References}

Adler, Stella. 1988. The Technique of Acting. New York: Bantam Books.

Balk, H. Wesley. 1977. The Complete Singer-Actor: training for music theatre. Minneapolis: University of Minnesota Press.

Benedetti, Jean. 1999. Stanislavski: his life and art. London: Methuen.

Bergman, Allison, and Moore, Tracey. 2008. Acting the Song: performance skills for the musical theatre. New York: Allworth Press.

Bunch, Meribeth. 1997. Dynamics of the Singing Voice. $4^{\text {th }}$ ed. Vienna; New York: SpringerVerlag.

Burgess, Thomas D. M., and Skilbeck, Nicholas. 2000. The Singing and Acting Handbook: games and exercises for the performer. London: Routledge.

Caldarone, Marina, and Lloyd-Williams, Maggie. 2004. Actions: the actor's thesaurus. London: Nick Hern.

Carnicke, Sharon Marie. 2009. Stanislavsky in Focus: an acting master for the twenty-first century. $2^{\text {nd }}$ ed. London; New York: Routledge.

Carnicke, Sharon Marie, and Rosen, David. 2014. 'A Singer Prepares: Stanislavsky and Opera'. In R. Andrew White (ed.), The Routledge Companion to Stanislavsky. London: Routledge, pp. 120-38.

Deer, Joe, and Dal Vera, Rocco. 2008. Acting in Musical Theatre: a comprehensive course. London; New York: Routledge.

Gillett, John. 2014. Acting Stanislavski: a practical guide to Stanislavski's approach and legacy. London: Bloomsbury.

Gutekunst, Christina, and Gillett, John. 2014. Voice into Acting: integrating voice and the Stanislavski approach. London: Bloomsbury.

Harvard, Paul. 2013. Acting Through Song. London: Nick Hern.

Hodge, Alison (ed.). 2000. Twentieth-Century Actor Training. London; New York: Routledge.

Krasner, David. 2014. 'The System, Sense-Emotion Memory, and Physical Action/Active Analysis: American interpretations of the system's legacy'. In R. Andrew White (ed.), The Routledge Companion to Stanislavsky. London: Routledge, pp. 195-212.

Linklater, Kristin. 2006. Freeing the Natural Voice: imagery and art in the practice of voice and language. London: Nick Hern Books.

Merlin, Bella. 2007. The Complete Stanislavsky Toolkit. London: Nick Hern. 
Ostwald. David F. 2005. Acting for Singers: creating believable singing characters. Oxford: Oxford University Press.

Panet, Brigid. 2009. Essential Acting: a practical handbook for actors, teachers and directors. New York: Routledge.

Renard, Lissa Tyler. 2014. 'A Singer Prepares: Stanislavsky and Opera'. In R. Andrew White (ed.), The Routledge Companion to Stanislavsky. London: Routledge. pp. 120-38.

Rodenburg, Patsy. 1993. The Need for Words: voice and the text. London: Methuen Drama.

Stanislavsky, Konstantin. 2010. An Actor's Work, trans. Jean Benedetti. London: Routledge.

Streeton, Jane, and Raymond, Philip. 2014. Singing on Stage: an actor's guide. London: Bloomsbury.

White, R. Andrew (ed.). 2014.The Routledge Companion to Stanislavsky. London: Routledge.

Yakim, Moni. 1993. Creating a Character: a physical approach to acting. New York: Applause.

Zinder, David. 2013. Body Voice Image: imagework training and the Chekhov technique. Hoboken, New Jersey: Taylor and Francis. 